\title{
Unexpectedly high early prevalence of anaemia in 6-month-old breast-fed infants in rural Bangladesh
}

\author{
Yaseer A Shakur ${ }^{1, *}$, Nuzhat Choudhury ${ }^{2}$, SM Ziauddin Hyder ${ }^{3}$ and Stanley H Zlotkin ${ }^{4}$ \\ ${ }^{1} T$ he Hospital for Sick Children, Room 8438, 555 University Avenue, Toronto, Ontario, Canada, M5G 1X8: \\ ${ }^{2}$ Nutrition Division, BRAC (Building Resources Across the Community), Dhaka, Bangladesh: ${ }^{3}$ Department of \\ Public Health Sciences, University of Toronto, Toronto, Ontario, Canada: ${ }^{4}$ The Hospital for Sick Children, \\ Departments of Pediatrics, Nutritional Sciences, and Public Health Sciences, University of Toronto, Toronto, \\ Ontario, Canada
}

Submitted 21 July 2008: Accepted 4 March 2009: First published online 28 May 2009

\begin{abstract}
Objective: To determine the prevalence of anaemia and maternal and infant factors associated with $\mathrm{Hb}$ values in infants at 6 months of age in rural Bangladesh. Design: Infants (born to mothers supplemented with Fe-folic acid from midpregnancy) were visited at birth and 6 months of age. Mothers' anthropometric status, and infants' birth weight, gestational age at birth, weight and $\mathrm{Hb}$ concentration at 6 months were measured. Household socio-economic and demographic data, infant feeding practices and health status were collected using a pre-tested structured questionnaire.

Setting: Rural Bangladesh.

Subjects: Four hundred and two infants.

Results: For the total cohort ( $n$ 402), the range of anaemia prevalence values was from $30.6 \%$ using a cut-off value of $\mathrm{Hb}<95 \mathrm{~g} / \mathrm{l}$ to $71.9 \%$ using a value of $\mathrm{Hb}<110 \mathrm{~g} / \mathrm{l}$. Birth weight and month of birth were the only factors positively associated with infant $\mathrm{Hb}$ in a linear regression model $(P=0 \cdot 008$ and $0 \cdot 011$, respectively).

Conclusions: There was an unexpectedly high prevalence of anaemia in infants at 6 months of age, before the assumed period of vulnerability. $\mathrm{Hb}$ at this age tended to be higher in those with higher birth weight. We also found a season effect on $\mathrm{Hb}$, as it tended to be higher as the study progressed. The high prevalence of anaemia at such an early age needs to be addressed to minimize the disease's long-term consequences.
\end{abstract}

Anaemia due to Fe deficiency remains the most common preventable nutritional deficiency in the world ${ }^{(1)}$. Anaemia has negative consequences in all age groups; in adults, it leads to fatigue and reduced work capacity, while in infants it is associated with compromised motor and mental function that may not be reversible ${ }^{(2,3)}$. The aetiology of Fedeficiency anaemia in infants between 6 and 24 months of age is multi-factorial, including low content and bioavailability of Fe in unfortified complementary foods, depressed absorption of $\mathrm{Fe}$ due to chronic infection, rapid growth during this period and possibly early cord clamping ${ }^{(4-7)}$. Recommendations to introduce Fe-rich complementary foods after 6 months of age are partly based on the observation that in the full-term infant, it is expected that the combination of Fe stores at birth plus the minimal but highly bioavailable contribution from breast milk should suffice to meet the Fe needs of most infants up to 6 months of age ${ }^{(8)}$. It is after this time that infants are thought to be at risk of anaemia. In fact, daily $\mathrm{Fe}$ supplementation $(12.5 \mathrm{mg}$ of elemental $\mathrm{Fe}$ ) is recommended for all infants between the ages of 6 and 24 months in areas where the prevalence of anaemia exceeds $40 \%{ }^{(9)}$.

Compared with infants in developed countries, it has been observed that anaemia may be prevalent at or before 6 months of age in infants in developing countries $^{(10-12)}$. For example, high anaemia (defined as $\mathrm{Hb}<$ $110 \mathrm{~g} / \mathrm{l})$ prevalence was documented at 6 months of age in infants in Jordan and Israel (63\% and 44\%, respectively $)^{(10,11)}$. Additionally, a $42 \%$ prevalence of anaemia has been documented in 4-month-old infants in a recent study in Benin ${ }^{(12)}$. Given the potential adverse effects of Fe-deficiency anaemia on infant development, from a public health perspective primary prevention would be preferable to screening and treatment. However, if anaemia onset is prior to 6 months of age, new recommendations for early prevention may be needed. 
Rates of poverty and malnutrition are high in rural Bangladesh ${ }^{(13)}$, thus Bangladeshi infants are likely to be at high risk of early anaemia. To our knowledge, the prevalence of anaemia in infants at age 6 months has not been documented in this setting. Additionally, while it is known that birth weight is associated with Fe status in infancy, associations with other factors have not been clearly established ${ }^{(14-16)}$. Thus the objectives of the current study were to determine the prevalence of anaemia in Bangladeshi infants at 6 months of age and to identify maternal and infant factors associated with $\mathrm{Hb}$ concentration at this age. The study was largely exploratory. Nevertheless, we tentatively hypothesized that there would be a high prevalence of anaemia at this age and that both infant and maternal factors would contribute to $\mathrm{Hb}$ concentration at 6 months of age.

\section{Methods}

\section{Setting}

The study took place in Kaliganj, a rural sub-district in the Gazipur district of Bangladesh, $40 \mathrm{~km}$ north-east of Dhaka. Kaliganj is a fair representation of the geo-ecological attributes of the rural plains in Bangladesh, with high population density and fertile agricultural land that is vulnerable to seasonal floods ${ }^{(17)}$. Like most of rural Bangladesh, poverty and malnutrition are widespread in Kaliganj, and women and children bear the brunt of it ${ }^{(17)}$. There is still relatively limited access to health care and $75 \%$ of women and $70 \%$ of men do not have education beyond the elementary level ${ }^{(17)}$. The infant mortality rate and prevalence of low birth weight (LBW) are similar to the national averages for Bangladesh ${ }^{(18)}$. The study took place between March 2005 and April 2007 and was carried out as an academic collaboration between The Hospital for Sick Children, Toronto, Canada and the Research and Evaluation Division of BRAC (Building Resources Across the Community), Dhaka, Bangladesh.

\section{Study design and participants}

The study was a prospective cohort study whose sample consisted of 424 infants born to all of the mothers participating in a randomized, controlled, pregnancy supplementation trial comparing two groups of pregnant women receiving $\mathrm{Fe}$ and folic acid supplements delivered in the form of Sprinkles ${ }^{\mathrm{TM}}$ or tablets. In both treatment arms, from mid-pregnancy onwards, the women received daily supplementation containing the same amounts of elemental Fe $(60 \mathrm{mg})$ and folic acid $(400 \mu \mathrm{g})$. Thus, in the current study, infants from mothers in the two treatment groups were combined and treated as one cohort; however, all analyses controlled for the form of supplementation. The infants were visited at birth and then again at 6 months of age. Infants were included if their mother was a permanent resident in the study area, participated in the original study and provided informed consent. Infants were excluded if they had a birth defect or serious condition that required hospitalization, they were not singletons, they received Fe supplementation, infant mortality/ stillbirth occurred, or if any of the inclusion criteria were not met.

\section{Data collection}

Mother's age, $\mathrm{Hb}$, weight and height were measured at the mid-pregnancy recruitment visit (14 to 20 weeks' gestation; referred to henceforth as baseline). At this visit, gestational age was also calculated based on the last menstrual period (LMP) recall method ${ }^{(19)}$. At birth, the weight of the infant was measured and gestational age determined based on the calculation from the initial recruitment visit. At 6 months of age, the weight and $\mathrm{Hb}$ concentration of each infant were measured. At the same time, data on parity, child spacing, socio-economic status, feeding practices (prevalence and duration of exclusive breast-feeding (EBF)) and general health status were collected via a pre-tested questionnaire administered to the mother. EBF was defined as feeding/having been fed nothing other than breast milk. Data on general health were obtained by collecting information on immunization and prevalence of diarrhoea. One incidence of diarrhoea was defined as the passage of three or more loose/watery stools in a single day. Additionally, the mother's and interviewer's perception of the child's current state of health was collected. There is no consensus as to the anaemia cut-off at 6 months of age. While we present anaemia prevalence using several $\mathrm{Hb}$ cut-off values from the literature ${ }^{(20-22)}$, the $\mathrm{WHO}$ definition of anaemia $(\mathrm{Hb}<110 \mathrm{~g} / \mathrm{l})$ is taken as the standard for the purposes of the present study. For pregnant mothers, anaemia was defined as $\mathrm{Hb}<110 \mathrm{~g} / \mathrm{l}^{(21)}$. Severe anaemia was defined as $\mathrm{Hb}<70 \mathrm{~g} / \mathrm{l}^{(21)}$. Any child found to be anaemic $(\mathrm{Hb}<$ $110 \mathrm{~g} / \mathrm{l})$ at 6 months of age was referred to a BRAC community health worker or local health practitioner for Fe supplementation.

$\mathrm{Hb}$ was measured in the field from a finger-prick capillary blood sample using a portable $\mathrm{HemoCue}{ }^{\circledR}$ $\beta$-Hemoglobin Photometer (HemoCue, Angelholm, Sweden). The CV of the photometer was $1.5 \%$. The technique is well established and was carried out as previously described by Meinzen-Derr et al. ${ }^{(23)}$. All weight measurements were completed using the UNISCALE (UNICEF Supply Division, Copenhagen, Denmark), which is accurate to $100 \mathrm{~g}$, except for birth weight, which was measured using the hanging Salter-like scale (UNICEF Supply Division) that is accurate to $50 \mathrm{~g}$. Both techniques have been described before ${ }^{(24)}$.

\section{Statistical analysis}

All data forms were collected and checked for completeness before being entered into the storage database. Data were entered, stored and analysed using version 
$14 \cdot 0$ of the SPSS for Windows statistical software package (SPSS Inc., Chicago, IL, USA). The subject population and hence the sample size for the present study was derived from the original $\mathrm{Fe}$-folic acid pregnancy supplementation study (the infants born to the 424 women). Nevertheless, in order to detect a prevalence of anaemia with $95 \%$ confidence that was within $5 \%$ of the true prevalence and assuming that the population of infants in Kaliganj was $6500^{(18)}, 363$ infants would need to have been screened at 6 months of age. A one-sample Kolmogorov-Smirnov test was used to verify normality of the infants' $\mathrm{Hb}$ concentrations, the main outcome measure, and that of the other continuous variables collected; variables that were not normally distributed were log-transformed before analyses. Correlation matrices were generated to identify variables correlated with $\mathrm{Hb}$ concentration at 6 months of age. For continuous variables that were normally distributed, Pearson correlation values are presented, while for discrete, non-normal variables, Spearman's rho correlation coefficients are presented. To detect associations, linear regression analysis was performed with $\mathrm{Hb}$ and birth weight as dependent variables in separate models. A subanalysis was performed on LBW infants to identify factors

Table 1 Characteristics of mothers ( $n$ 402), Kaliganj sub-district, Bangladesh, March 2005 to April 2007

\begin{tabular}{|c|c|c|c|}
\hline Characteristic & Mean & SD & Range \\
\hline Household size & $5 \cdot 7$ & $2 \cdot 4$ & 2,17 \\
\hline No. of living children & $1 \cdot 8$ & $1 \cdot 1$ & 1,7 \\
\hline Total no. of conceptions* & $2 \cdot 1$ & $1 \cdot 3$ & 1,8 \\
\hline Average child spacingt (months) & $51 \cdot 1$ & $22 \cdot 6$ & 17,162 \\
\hline Time from last child (months) & $55 \cdot 1$ & $27 \cdot 0$ & 17,162 \\
\hline Age at first pregnancy (years) & $18 \cdot 4$ & $2 \cdot 7$ & 14,32 \\
\hline Age $\$$ (years) & $22 \cdot 2$ & $5 \cdot 0$ & 14,44 \\
\hline Total years of education & $6 \cdot 5$ & $3 \cdot 3$ & 0,14 \\
\hline Weight§ (kg) & $46 \cdot 4$ & $7 \cdot 0$ & $28 \cdot 3,77 \cdot 4$ \\
\hline Heights (cm) & $150 \cdot 2$ & $5 \cdot 5$ & $132 \cdot 1,168 \cdot 5$ \\
\hline BMI§ $\left(\mathrm{kg} / \mathrm{m}^{2}\right)$ & $20 \cdot 5$ & $2 \cdot 7$ & $13 \cdot 5,34 \cdot 2$ \\
\hline $\mathrm{Hb} \S(\mathrm{g} / \mathrm{l})$ & $110 \cdot 4$ & $14 \cdot 3$ & 72,150 \\
\hline
\end{tabular}

*The total number of times the mother knew she was pregnant, regardless of outcome.

tFor women with previous children; calculated by taking the difference between the eldest and youngest child and dividing by one less than the total number of children. Stillbirths and neonatal deaths were not taken into account in this calculation.

$\ddagger$ For women with previous children; calculated by taking the difference between the second youngest and youngest child.

§Measurement taken at 14-20 weeks' gestation; referred to as 'baseline'. associated with $\mathrm{Hb}$ and anaemia in this group. In all analyses, statistical significance was defined as $P<0 \cdot 05$.

\section{Etbics approval}

The study protocol was approved by the Research Ethics Board at The Hospital for Sick Children (Toronto, Canada) and the Ethics Board of the Bangladesh Medical Research Council (Dhaka, Bangladesh).

\section{Results}

A summary of the maternal characteristics is presented in Table 1. Data were analysed for 402 mother-infant pairs. Twenty-two pairs were excluded from the analysis due to stillbirth ( $n$ 3), infant mortality ( $n$ 6), twin birth $(n 1)$ or relocation ( $n$ 12) from the study area. This was the first child for 194 of the mothers in the study. Therefore, for the variables 'child spacing' and 'time since the last child', data are presented only for those with one or more previous children. At recruitment, $45 \cdot 3 \%$ (182/402) of the mothers were anaemic, but none had severe anaemia. Ninety-seven $(24 \cdot 1 \%)$ mothers reported their perceived economic status as 'above average'.

Table 2 presents data on infant characteristics. There were 205 (51\%) male and 197 (49\%) female infants. For logistical reasons, we were unable to collect birth weight from 117 of the 402 infants. In infants with a known birth weight, the prevalence of LBW $(<2 \cdot 5 \mathrm{~kg})$ was $36 \cdot 1 \%(103 / 285)$. Of these infants, $21 \cdot 4 \%(22 / 103)$ were born preterm $(<37$ weeks' gestation). At 6 months of age, of the 182 infants with normal birth weight, only nine $(4.9 \%)$ were significantly underweight (weight-for-age $Z$-score $<-2$ ), while thirty of the $103 \mathrm{LBW}$ infants $(29 \cdot 1 \%)$ were also significantly underweight; LBW infants were more likely to be underweight at 6 months of age (unadjusted $\mathrm{OR}=7 \cdot 9,95 \% \mathrm{CI}$ $3 \cdot 6,17 \cdot 5 ; P=0 \cdot 000)$. The prevalence of EBF at 6 months of age was only $1.7 \%(7 / 402)$, while the mean duration of EBF was $70 \cdot 3 \mathrm{~d}$ (SD $61 \cdot 6 \mathrm{~d}$, interquartile range $119 \mathrm{~d}$ ). Most infants (98.5\%) had received at least one immunization. Fifty-seven infants $(14 \cdot 2 \%)$ experienced at least one bout of diarrhoea in the last $7 \mathrm{~d}$.

Given that there is disparity concerning the definition of anaemia at 6 months of age, Table 3 presents the

Table 2 Characteristics of infants born to mothers supplemented with Fe-folic acid from mid-pregnancy, Kaliganj sub-district, Bangladesh, March 2005 to April 2007

\begin{tabular}{|c|c|c|c|c|}
\hline Characteristic & $n$ & Mean & SD & Range \\
\hline Actual date of birth relative to expected $(d)$ & 402 & $3 \cdot 1$ & $19 \cdot 5$ & $-60,45$ \\
\hline Birth weight $(\mathrm{kg})$ & 285 & $2 \cdot 8$ & $0 \cdot 4$ & $1 \cdot 3,4 \cdot 5$ \\
\hline Weight at 6 months $(\mathrm{kg})$ & 402 & $6 \cdot 9$ & $0 \cdot 9$ & $4 \cdot 5,9 \cdot 9$ \\
\hline Growth rate (kg/month) & 285 & $0 \cdot 7$ & $0 \cdot 1$ & $0 \cdot 4,1 \cdot 1$ \\
\hline Growth ratio relative to birth weight $t$ & 285 & $2 \cdot 5$ & $0 \cdot 3$ & $1 \cdot 8,4 \cdot 0$ \\
\hline Weight-for-age $Z$-score at 6 months of age & 402 & $0 \cdot 9$ & $1 \cdot 0$ & $-4 \cdot 1,2 \cdot 5$ \\
\hline
\end{tabular}

${ }^{*}$ Negative indicates earlier than expected. Expected date of birth determined based on recall of last menstrual period. tCalculated by dividing the infant's weight at 6 months by his/her birth weight.

‡Based on the 2006 WHO growth charts. 
Table 3 Prevalence of anaemia at 6 months of age based on the different cut-off values in the literature: infants born to mothers supplemented with Fe-folic acid from mid-pregnancy, Kaliganj sub-district, Bangladesh, March 2005 to April 2007

\begin{tabular}{|c|c|c|c|c|}
\hline \multirow[b]{3}{*}{ Anaemia cut-off value* } & \multicolumn{4}{|c|}{ Prevalence of anaemia } \\
\hline & \multicolumn{2}{|c|}{ Total cohort of infants $(n$ 402) } & \multicolumn{2}{|c|}{ LBW infants $(n$ 103) } \\
\hline & $n$ & $\%$ & $n$ & $\%$ \\
\hline $\mathrm{Hb}<95 \mathrm{~g} / \mathrm{l}$ & 123 & $30 \cdot 6$ & 29 & $28 \cdot 2$ \\
\hline $\mathrm{Hb}<100 \mathrm{~g} / \mathrm{l}$ & 174 & $43 \cdot 3$ & 54 & $52 \cdot 4$ \\
\hline $\mathrm{Hb}<105 \mathrm{~g} / \mathrm{l}$ & 221 & $55 \cdot 0$ & 74 & $72 \cdot 8$ \\
\hline $\mathrm{Hb}<110 \mathrm{~g} / \mathrm{l}$ & 289 & 71.9 & 86 & 83.5 \\
\hline
\end{tabular}

LBW, low birth weight.

${ }^{*}$ Cut-off values reported by Virtanen et al. ${ }^{(22)}$, Domellof et al. ${ }^{(20)}$ and $\mathrm{WHO}^{(21)}$.

Table 4 Factors correlated with $\mathrm{Hb}$ concentration at 6 months of age among infants born to mothers supplemented with Fe-folic acid from mid-pregnancy, Kaliganj sub-district, Bangladesh, March 2005 to April 2007

\begin{tabular}{|c|c|c|}
\hline Factor & Correlation coefficient & $P$ value \\
\hline Birth weight* $(n$ 285) & 0.209 & 0.000 \\
\hline Growth ratio (weight at 6 months/birth weight) ${ }^{*}(n$ 285) & $-0 \cdot 195$ & 0.001 \\
\hline Water feedingt, $\ddagger$ ( $n$ 402) & $0 \cdot 116$ & 0.023 \\
\hline Month of birtht ( $n$ 402) & 0.209 & 0.000 \\
\hline Mother's age at first pregnancyt ( $n$ 402) & $0 \cdot 106$ & 0.033 \\
\hline Teenage mothert, $\ddagger$ ( $n$ 402) & $0 \cdot 111$ & 0.026 \\
\hline Mother's baseline aget ( $n$ 402) & $0 \cdot 117$ & $0 \cdot 019$ \\
\hline Mother's baseline BMIt ( $n$ 402) & $0 \cdot 104$ & $0 \cdot 037$ \\
\hline
\end{tabular}

*Pearson's $r$ correlation coefficient.

†Spearman's $\rho$ correlation coefficient.

$\ddagger$ Treated as a dichotomous variable $(1=$ yes, $2=$ no $)$

prevalence of anaemia in the infants based on the different $\mathrm{Hb}$ cut-off values described in the literature. For the total cohort ( $n$ 402), the range of anaemia prevalence values was from $30 \cdot 6 \%$ using a cut-off value of $\mathrm{Hb}<95 \mathrm{~g} / \mathrm{l}$ to $71.9 \%$ using a value of $\mathrm{Hb}<110 \mathrm{~g} / \mathrm{l}$ (the WHO definition of anaemia). For LBW infants ( $n$ 103), the range of anaemia prevalence was from $28.2 \%$ to $83.5 \%$ using the same cut-off values. Four infants (1\%) were severely anaemic. The mean $\mathrm{Hb}$ was $102 \cdot 3 \mathrm{~g} / \mathrm{l}$ (sD $12.4 \mathrm{~g} / \mathrm{l}$, range 64-134g/l). Table 4 summarizes factors significantly correlated with $\mathrm{Hb}$. The following notable variables were not correlated with the infants' $\mathrm{Hb}$ at 6 months: weight gain from birth to 6 months $(r=-0 \cdot 041 ; P=0 \cdot 486)$, gestational age at birth $(r=0.08 ; P=0 \cdot 114)$, duration of EBF $(r=0.022 ; P=0.664)$, mother's baseline age $(r=$ $0 \cdot 08 ; P=0 \cdot 108)$, mother's weight $(r=0 \cdot 076 ; P=0 \cdot 128)$, mother's height $(r=0.009 ; P=0.853)$ and mother's $\mathrm{Hb}$ ( $r=0.07 ; \quad P=0 \cdot 161$ ). Additionally, none of the infant health indices were correlated with $\mathrm{Hb}$ at 6 months. After adjusting for infant gender, the birth of previous children, duration of gestation, mother's treatment group and mother's baseline $\mathrm{Hb}$, the only significant predictors in the linear regression model (model $R^{2}=10 \cdot 4 \%$; $P=0.000)$ of $\mathrm{Hb}$ at 6 months of age were infant birth weight (standardized $\beta=0.214 ; P=0.000$ ) and month of birth (standardized $\beta=0 \cdot 171 ; P=0 \cdot 011$; Table 5). Removing LBW infants from the analysis did not alter the significance of any factor.
Table 5 General linear model ${ }^{*}$ with infant $\mathrm{Hb}$ concentration at 6 months of age as the response variable

\begin{tabular}{lccc}
\hline Predictor variable & Standardized $\beta$ & $t$ statistic & $P$ value \\
\hline Birth weight & 0.214 & 3.23 & 0.000 \\
Month of birth & 0.171 & 2.83 & 0.011 \\
Infant gendert & 0.044 & 0.75 & 0.46 \\
First pregnancy & -0.034 & -0.58 & 0.57 \\
Duration of gestation & -0.042 & -0.67 & 0.50 \\
Mother's baseline Hb & 0.039 & 0.65 & 0.52 \\
Mother's treatment group & -0.001 & -0.014 & 0.99
\end{tabular}

*Model's adjusted $R^{2}=10.4 \%(P=0.000)$.

tMale $=1$, female $=2$.

$\ddagger$ Treated as a dichotomous variable $(1=$ yes, $2=$ no $)$.

For LBW infants, stepwise linear regression analysis (forward; $P$ value for retention $<0.05$ ) revealed that absolute weight gain from birth to 6 months (negatively associated; standardized $\beta=-0.42$; model $R^{2}=17.6 \%$; $P=0 \cdot 001$ ) was the only significant predictor of $\mathrm{Hb}$ at 6 months of age.

\section{Discussion}

The high prevalence of anaemia in infants at 6 months of age born to Fe-supplemented mothers in the present study highlights a significant health problem in rural Bangladesh. The most vulnerable period for Fe deficiency and anaemia in full-term infants is between 6 and 24 months, and $\mathrm{Hb}$ is 
thought to reach its minimum at 9 months of age ${ }^{(25)}$. It is during this period that blanket Fe supplementation programmes are recommended in populations with a known prevalence of anaemia (defined as $\mathrm{Hb}<110 \mathrm{~g} / \mathrm{l}$ ) of over $40 \%{ }^{(21)}$. However, in the present study, over $70 \%$ of infants would be classified as anaemic based on this cut-off value. Even with a more conservative anaemia cutoff $(\mathrm{Hb}<105 \mathrm{~g} / \mathrm{l}), 55 \%$ of infants were already anaemic even by 6 months of age. Thus, these infants are already exposed to the negative consequences of anaemia before they enter this known period of vulnerability. In developed countries, Fe supplementation is only recommended before 6 months of age for LBW infants, and even then adherence to this recommendation is low ${ }^{(23,26)}$. However, there are no strategies for Fe supplementation of LBW infants in developing countries other than EBF.

There is some debate as to the anaemia cut-off value at 6 months of age ${ }^{(20-22)}$. Therefore, we present anaemia prevalence based on various proposed cut-off values (Table 3). The prevalence of anaemia based on the WHO cut-off of $\mathrm{Hb}<110 \mathrm{~g} / \mathrm{l}$ is alarmingly high (71.9\%), almost double that required for the WHO's blanket Fe supplementation recommendations. Nevertheless, using the most conservative cut-off $(\mathrm{Hb}<95 \mathrm{~g} / \mathrm{l})$, nearly one-third of infants would still be classified as anaemic. At the cutoff suggested by Domellof et $a l^{(20)}$, in which they report $105 \mathrm{~g} / 1$ as the mean minus two standard deviations in a cohort of Fe-replete infants, more than half of infants at age 6 months would be classified as anaemic in the present study. However, until there is scientific agreement on a new standard, we continue to use the WHO cut-off for anaemia at this age.

After controlling for confounding variables, birth weight and month of birth were the only infant factors significantly associated (both positively) with $\mathrm{Hb}$ concentration at 6 months of age. This confirms previous findings which document the impact of birth weight on body $\mathrm{Fe}$ stores and $\mathrm{Hb}$ concentration ${ }^{(14-16)}$. Babies with LBW, whether because of prematurity or because they are small for gestational age, have lower Fe stores. Thus it makes sense that they will become Fe-depleted at an earlier age. The observed association between $\mathrm{Hb}$ and birth month is somewhat hard to explain but may be attributed to environmental effects. Infants in the current study were born between January and September 2006. Therefore, the 6-month $\mathrm{Hb}$ measurement took place between July 2006 and March 2007. As the months progressed, there was a trend toward increasing $\mathrm{Hb}$ among the infants. In rural Bangladesh, January, February and March are post-harvest months. During these months there is an abundance of inexpensive fruits available to all. As a result, the vitamin C consumption in these infants, the majority of whom were not exclusively breastfed, was likely higher, possibly leading to higher Fe absorption. Alternatively, the earlier months of $\mathrm{Hb}$ measurement (July, August and September) are during the monsoon season, when rates of infection are likely higher. However, it must be noted that the prevalence of anaemia (defined as $\mathrm{Hb}<110 \mathrm{~g} / \mathrm{l}$ ) was still over $44 \cdot 7 \%$ (51/114) in the latter months of the study. Seasonal variation in anaemia prevalence has not been well documented in children; however, among pregnant Nepali women, variation in anaemia rates was attributed to limitations in availability of food along with increased intestinal infections during the Nepali monsoon season ${ }^{(27)}$. In infants born in malaria-endemic areas of Africa, seasonal variation in anaemia has been attributed to malaria ${ }^{(28,29)}$. However, malaria prevalence is low in Kaliganj and not likely a contributor ${ }^{(17)}$.

Absolute weight gain was not associated with $\mathrm{Hb}$ concentration at 6 months in the entire cohort of infants but was negatively associated with $\mathrm{Hb}$ in LBW infants. It has been previously documented that weight gain is negatively associated with Fe status in infancy ${ }^{(14,15,30,31)}$. Blood volume and weight gain are thought to be linearly associated in infancy, as infants typically triple both their weight and their blood volume in the first year of life ${ }^{(32)}$. Consequently, the more rapid the weight gain, the greater is the need for Fe to keep up with the rapid expansion of the blood volume. This in turn should translate into a lower $\mathrm{Hb}$ concentration. We did not measure serum ferritin concentration in our study, and thus are unable to comment on an association between weight gain and Fe stores. Although Fe status was not measured, we assume that the primary cause of anaemia was Fe deficiency since the typical complementary foods used in rural Bangladesh are low in bioavailable Fe and not fortified, and animalbased foods rich in Fe are rarely provided to infants ${ }^{(33)}$.

We did not find an association between duration of EBF and $\mathrm{Hb}$ at 6 months of age; however, the duration of EBF was very short among a large proportion of mothers in this cohort and the prevalence of EBF at 6 months of age was very low. This resulted in a highly skewed distribution of duration of EBF, and therefore an insufficient number of mothers who practised EBF into the fifth and sixth months. It has been previously reported that the prevalence of $\mathrm{EBF}$ at 6 months of age is $29 \%$ across Bangladesh ${ }^{(34)}$. However, Roy et al. found a $7 \cdot 7 \%$ prevalence of $\mathrm{EBF}$ at 6 months in the capital city, Dhaka ${ }^{(35)}$. We expected that the prevalence of EBF would be much higher in the rural areas, especially since there is very limited access to breast milk substitutes, but this was not the case in our study. Not only would EBF benefit the infants in terms of the provision of passive immune factors and good nutrition, but EBF up to 6 months of age has been shown to impact positively on $\mathrm{Hb}$ status at 6 months of age ${ }^{(36,37)}$. However, given the feeding practices in our population, we were unable to detect any associations. The high prevalence of low EBF rates has been well documented in the past, leading to the implementation of a national programme in 1989 entitled the 'Campaign for Protection and Promotion of Breastfeeding 
(CPPBF), (38). This programme, now termed the BBF (Bangladesh Breastfeeding Foundation), aims to 'counter the delayed initiation of breastfeeding, administration of pre-lacteal foods, early complementary feeding, bottle feeding, and the very low rates of exclusive breastfeeding ${ }^{\text {(38) }}$. However, the programme, although implemented almost 20 years ago in Bangladesh, has yet to reach the sub-district of the present study's setting and many others in rural Bangladesh (F Haseen, personal communication).

As previously noted, there were no maternal factors significantly associated with $\mathrm{Hb}$ in the infants at age 6 months in the controlled linear regression model. In a previous study on 990 infants in rural Indonesia ${ }^{(39)}$, the authors found that 3- to 5-month-old infants born to anaemic mothers had significantly lower $\mathrm{Hb}$ concentrations than infants born to non-anaemic mothers. However, the authors did not specify at what point during the pregnancy $\mathrm{Hb}$ was measured in the mothers. The relationship between maternal haematological status during pregnancy and that of her infant has long been controversial, with some studies suggesting no association ${ }^{(40-42)}$ while others report a positive relationship ${ }^{(43-45)}$. It is feasible that $\mathrm{Hb}$ status in pregnancy would impact on anaemia prevalence in infants. Over $50 \%$ of maternal anaemia in the world is due to $\mathrm{Fe}$ deficiency ${ }^{(46)}$. The placenta is rich in transferrin receptors thus facilitating the transfer of Fe from the maternal to the fetal side of the placenta, often at the expense of the mother ${ }^{(47)}$. However, if the mother is severely Fe-depleted, it is highly likely that the net transfer of Fe will be affected $^{(48)}$. On the other hand, the fact that no association was observed between infant and maternal $\mathrm{Hb}$ in the current study more than likely reflects the fact that none of the mothers was severely anaemic.

There is a growing body of literature implicating the timing of cord clamping as an important factor influencing the Fe endowment of the infant, as it determines the amount of placental blood (and consequently $\mathrm{Fe}$ ) transferred to the child after birth. The authors of a meta-analysis of fifteen studies on cord clamping and Fe status concluded that cord clamping should be delayed for at least 2 min after birth to improve the Fe status of the newborn ${ }^{(49)}$. However, the general practice among traditional birth attendants in Bangladesh is to clamp the cord immediately after birth ${ }^{(50)}$. Unfortunately, data on the timing of umbilical cord clamping were not collected in the current study due to the complex logistics associated with home childbirth in a rural setting. Nevertheless, given the traditional practice in Bangladesh of early clamping, it is quite likely that this is a contributing factor to the high prevalence of early anaemia.

\section{Conclusion}

The high prevalence of anaemia in 6-month-old infants in rural Bangladesh is a serious public health problem, especially among LBW infants. To date, strategies to reduce anaemia prevalence have not been successful.
Anaemic infants entering the vulnerable period for $\mathrm{Fe}$ deficiency anaemia (6-24 months of age) have already been exposed and are likely to be further exposed to the negative consequences of anaemia. While birth weight is known to be associated with anaemia, there has been minimal success at lowering the prevalence of LBW in Bangladesh. Given the findings of the current study, there is a need for further research to understand the factors predisposing infants to early anaemia, and to examine why programmes to increase birth weight have not been successful.

\section{Acknowledgements}

The authors acknowledge the following sources of funding: (i) Y.A.S. was supported in part through a studentship by the Ontario Student Opportunity Trust Fund, The Hospital for Sick Children Foundation Student Scholarship Program; (ii) Y.A.S. was also supported through a Canada Graduate Scholarship Master's Award, Canadian Institutes of Health Research (CIHR), FRN 81770; and (iii) an H.J. Heinz Foundation Research Grant. There are no real or perceived potential conflicts of interest associated with the work. The first draft of the manuscript was written by the first author, Y.A.S. All authors were involved in study design and editing of the manuscript. Y.A.S. and N.C. planned and executed data collection. Y.A.S. and S.M.Z.H. performed the statistical analyses. S.H.Z. oversaw the entire study. We gratefully thank Mr Mizanur Rahman for his help in the translation involved with this work.

\section{References}

1. Faldella G, Corvaglia L, Lanari M \& Salvioli GP (2003) Iron balance and iron nutrition in infancy. Acta Paediatr Suppl 91, 82-85.

2. Lozoff B, Beard J, Connor J, Barbara F, Georgieff M \& Schallert T (2006) Long-lasting neural and behavioral effects of iron deficiency in infancy. Nutr Rev 64, 5 Pt 2, S34-S43.

3. Lozoff B, Brittenham GM, Wolf AW, McClish DK, Kuhnert PM, Jimenez E, Jimenez R, Mora LA, Gomez I \& Krauskoph D (1987) Iron deficiency anemia and iron therapy effects on infant developmental test performance. Pediatrics $\mathbf{7 9}$, 981-995.

4. Zlotkin S, Arthur P, Antwi KY \& Yeung G (2001) Treatment of anemia with microencapsulated ferrous fumarate plus ascorbic acid supplied as sprinkles to complementary (weaning) foods. Am J Clin Nutr 74, 791-795.

5. Oski FA (1993) Iron deficiency in infancy and childhood. N Engl J Med 329, 190-193.

6. Chaparro CM, Neufeld LM, Tena Alavez G, Eguia-Liz Cedillo R \& Dewey KG (2006) Effect of timing of umbilical cord clamping on iron status in Mexican infants: a randomised controlled trial. Lancet 367, 1997-2004.

7. Emhamed MO, van Rheenen P \& Brabin BJ (2004) The early effects of delayed cord clamping in term infants born to Libyan mothers. Trop Doct 34, 218-222.

8. Duncan B, Schifman RB, Corrigan JJ Jr \& Schaefer C (1985) Iron and the exclusively breast-fed infant from birth to six months. J Pediatr Gastroenterol Nutr 4, 421-425. 
9. International Nutritional Anemia Consultative Group/ World Health Organization/UNICEF (1990) Guidelines for the Use of Iron Supplements to Prevent and Treat Iron Deficiency Anemia. Washington, DC: ILSI.

10. Kilbride J, Baker TG, Parapia LA \& Khoury SA (2000) Incidence of iron-deficiency anaemia in infants in a prospective study in Jordan. Eur J Haematol 64, 231-236.

11. Lavon B, Tulchinsky TH, Preger M, Said R \& Kaufman S (1985) Iron deficiency anemia among Jewish and Arab infants at 6 and 12 months of age in Hadera, Israel. Isr J Med Sci 21, 107-112.

12. Rahimy MC, Fanou L, Somasse YE, Gangbo A, Ahouignan G \& Alihonou E (2007) When to start supplementary iron to prevent iron deficiency in early childhood in sub-Saharan Africa setting. Pediatr Blood Cancer 48, 544-549.

13. Bhuiya A, Mahmood SS, Rana AK, Wahed T, Ahmed SM \& Chowdhury AM (2007) A multidimensional approach to measure poverty in rural Bangladesh. J Health Popul Nutr 25, 134-145.

14. Sherriff A, Emond A, Hawkins N \& Golding J (1999) Haemoglobin and ferritin concentrations in children aged 12 and 18 months. ALSPAC Children in Focus Study Team. Arch Dis Child 80, 153-157.

15. Gunnarsson BS, Thorsdottir I \& Palsson G (2004) Iron status in 2-year-old Icelandic children and associations with dietary intake and growth. Eur J Clin Nutr 58, 901-906.

16. Gunnarsson BS, Thorsdottir I \& Palsson G (2005) Iron status in 6-y-old children: associations with growth and earlier iron status. Eur J Clin Nutr 59, 761-767.

17. Karim F, Choudhury N, Pasha A, Hasan K, Hyder SM \& Zlotkin S (2006) Reaching Sprinkles to Millions: Social Marketing Strategy for Combating Childhood Iron Deficiency Anemia. Dhaka: BRAC.

18. Central Intelligence Agency (2007) World Fact Book. Bangladesh. https://www.cia.gov/cia/publications/factbook/ geos/bg.html (accessed March 2007).

19. Berg AT (1991) Menstrual cycle length and the calculation of gestational age. Am J Epidemiol 133, 585-589.

20. Domellof M, Dewey KG, Lonnerdal B, Cohen RJ \& Hernell O (2002) The diagnostic criteria for iron deficiency in infants should be reevaluated. J Nutr 132, 3680-3686.

21. World Health Organization (2004) Iron Deficiency Anemia. http://www.who.int/nutrition/topics/ida/en/index.html (accessed July 2007).

22. Virtanen A, Kairisto V, Irjala K, Rajamaki A \& Uusipaikka E (1998) Regression-based reference limits and their reliability: example on hemoglobin during the first year of life. Clin Chem 44, 327-335.

23. Meinzen-Derr JK, Guerrero ML, Altaye M, Ortega-Gallegos H, Ruiz-Palacios GM \& Morrow AL (2006) Risk of infant anemia is associated with exclusive breast-feeding and maternal anemia in a Mexican cohort. J Nutr 136, 452-458.

24. Food and Nutrition Technical Assistance Project (2006) Taking Measurements. http://www.fantaproject.org/down loads/pdfs/anthro_5.pdf (accessed January 2007).

25. Feightner JW (1994) Prevention of iron deficiency anemia in infants. In The Canadian Guide to Clinical Preventive Health Care, pp. 232-242. Ottawa: Canadian Task Force on the Periodic Health Examination.

26. Dewey KG, Cohen RJ \& Brown KH (2004) Exclusive breastfeeding for 6 months, with iron supplementation, maintains adequate micronutrient status among term, low-birthweight, breast-fed infants in Honduras. J Nutr 134, 1091-1098.

27. Bondevik GT, Lie RT, Ulstein M \& Kvale G (2000) Seasonal variation in risk of anemia among pregnant Nepali women. Int J Gynaecol Obstet 69, 215-222.

28. Koram KA, Owusu-Agyei S, Utz G, Binka FN, Baird JK, Hoffman SL \& Nkrumah FK (2000) Severe anemia in young children after high and low malaria transmission seasons in the Kassena-Nankana district of northern Ghana. Am J Trop Med Hyg 62, 670-674.

29. Ehrhardt S, Burchard GD, Mantel C, Cramer JP, Kaiser S, Kubo M, Otchwemah RN, Bienzle U \& Mockenhaupt FP (2006) Malaria, anemia, and malnutrition in African children - defining intervention priorities. J Infect Dis 194, 108-114.

30. Morton RE, Nysenbaum A \& Price K (1988) Iron status in the first year of life. J Pediatr Gastroenterol Nutr 7, 707-712.

31. Thorsdottir I, Gunnarsson BS, Atladottir H, Michaelsen KF \& Palsson G (2003) Iron status at 12 months of age - effects of body size, growth and diet in a population with high birth weight. Eur J Clin Nutr 57, 505-513.

32. Shabib SM (2006) Meeting the iron needs of infants and young children. Ann Saudi Med 16, 607-608.

33. Kimmons JE, Dewey KG, Haque E, Chakraborty J, Osendarp SJ \& Brown KH (2005) Low nutrient intakes among infants in rural Bangladesh are attributable to low intake and micronutrient density of complementary foods. J Nutr 135, 444-451.

34. Bangladesh Breastfeeding Foundation (2001) Surveillance on Breastfeeding and Weaning Situation and Child and Mother Health in Bangladesh: 6th Round Survey, pp. 13-15. Dhaka: Bangladesh Breastfeeding Foundation.

35. Roy SK, de Groot S, Shafique S \& Afroz A (2002) Perceptions of mothers and use of breastmilk substitutes in Dhaka, Bangladesh. J Health Popul Nutr 20, 264-270.

36. Dewey KG, Cohen RJ, Rivera LL \& Brown KH (1998) Effects of age of introduction of complementary foods on iron status of breast-fed infants in Honduras. Am J Clin Nutr 67, 878-884.

37. Raj S, Faridi M, Rusia U \& Singh O (2008) A prospective study of iron status in exclusively breastfed term infants up to 6 months of age. Int Breastfeed J 3, 3 .

38. Haider R, Kabir I \& Ashworth A (1999) Are breastfeeding promotion messages influencing mothers in Bangladesh? Results from an urban survey in Dhaka, Bangladesh. J Trop Pediatr 45, 315-318.

39. De Pee S, Bloem MW, Sari M, Kiess L, Yip R \& Kosen S (2002) The high prevalence of low hemoglobin concentration among Indonesian infants aged 3-5 months is related to maternal anemia. J Nutr 132, 2215-2221.

40. Gebre-Medhin M \& Birgegard G (1981) Serum ferritin in Ethiopian mothers and their newborn infants. Relation to iron intake and socio-economic conditions. Scand J Haematol 27, 247-252.

41. Wong CT \& Saha N (1990) Inter-relationships of storage iron in the mother, the placenta and the newborn. Acta Obstet Gynecol Scand 69, 613-616.

42. Murray MJ, Murray AB, Murray NJ \& Murray MB (1978) The effect of iron status of Nigerien mothers on that of their infants at birth and 6 months, and on the concentration of Fe in breast milk. BrJ Nutr 39, 627-630.

43. Colomer J, Colomer C, Gutierrez D, Jubert A, Nolasco A, Donat J, Fernandez-Delgado R, Donat F \& Alvarez-Dardet C (1990) Anaemia during pregnancy as a risk factor for infant iron deficiency: report from the Valencia Infant Anaemia Cohort (VIAC) study. Paediatr Perinat Epidemiol 4, 196-204.

44. Preziosi P, Prual A, Galan P, Daouda H, Boureima H \& Hercberg S (1997) Effect of iron supplementation on the iron status of pregnant women: consequences for newborns. Am J Clin Nutr 66, 1178-1182.

45. Milman N, Ibsen KK \& Christensen JM (1987) Serum ferritin and iron status in mothers and newborn infants. Acta Obstet Gynecol Scand 66, 205-211.

46. Beard JL (2000) Effectiveness and strategies of iron supplementation during pregnancy. Am J Clin Nutr 71, 5 Suppl., 1288S-1294S. 
47. Blot I, Diallo D \& Tchernia G (1999) Iron deficiency in pregnancy: effects on the newborn. Curr Opin Hematol 6 , 65-70.

48. Singla PN, Chand S, Khanna S \& Agarwal KN (1978) Effect of maternal anaemia on the placenta and the newborn infant. Acta Paediatr Scand 67, 645-648.
49. Hutton EK \& Hassan ES (2007) Late vs early clamping of the umbilical cord in full-term neonates: systematic review and meta-analysis of controlled trials. JAMA 297, 1241-1252.

50. Hoque A \& Selwyn BJ (1996) Birth practice patterns in urban slums of Dhaka, Bangladesh. Women Health 24 , $41-58$. 